\title{
Cascading Key Performance Indicator dan Perumusan Strategy Map Berbasis Balanced Scorecard
}

\author{
Cindy Ade Mei Arlina, Arman Hakim Nasution, dan Syarifa Hanoum \\ Departemen Manajemen Bisnis, Fakultas Bisnis dan Manajemen Teknologi, \\ Institut Teknologi Sepuluh Nopember (ITS) \\ e-mail: cindy.adelina05@gmail.com
}

\begin{abstract}
Abstrak-PT Boma Bisma Indra (BBI) merupakan salah satu BUMN yang bergerak dalam bidang Manufaktur Peralatan Industri (MPI) dan Manajemen Proyek dan Jasa (MPJ). Salah satu kegiatan yang penting bagi perusahaan adalah dengan melakukan perbaikan pengukuran kinerja. Metode yang digunakan adalah Balanced Scorecard dengan melakukan cascading dari strategi perusahaan hingga level departemen pada divisi MPJ, pebobotan menggunakan Analytical Hierarchy Process (AHP), dan uji coba pengukuran kinerja menggunakan Traffic Light System. Penelitian ini menghasilkan strategy map divisi MPJ, strategy map departemen Engineering, dan strategy map departemen Konstruksi. Dihasilkan pula 16 sasaran strategis dan 21 KPI divisi MPJ, 8 sasaran strategis dan 10 KPI departemen Engineering, dan 9 sasaran strategis dan 10 KPI departemen Konstruksi. Hasil uji coba pengukuran kinerja divisi MPJ adalah 15 KPI berwarna hijau, 1 KPI berwarna kuning, dan 5 KPI berawarna merah.
\end{abstract}

Kata Kunci-Analytical Hierarchy Process, Balanced Scorecard, Cascading, Strategy Map.

\section{PENDAHULUAN}

$\mathrm{P}$ T Boma Bisma Indra (BBI) merupakan salah satu BUMN yang bergerak dalam bidang manufaktur peralatan industri, agro industri, manajemen proyek, sarana dan prasarana industri, jasa dan perdagangan, dan industri permesinan. Perusahaan milik negara yang dikelompokkan dalam BUMN strategis ini menjalankan usahanya dalam pengerjaan proyek perekayasaan, pengadaan, dan konstruksi, atau lebih dikenal dengan istilah Engineering, Procurement, and Construction (EPC) yang menghasilkan produk-produk yang berperan penting dalam infrastruktur dan pertahanan negara. PT Boma Bisma Indra memiliki dua divisi yang merupakan core bisnis perusahaan, divisi tersebut diantaranya adalah Manufaktur Peralatan Industri (MPI) dan Manajemen Proyek dan Jasa (MPJ).

Setelah dilakukan beberapa studi dengan tujuan untuk terus meningkatkan perusahaan pada kondisi yang sehat, didapatkan beberapa permasalahan dari perusahaan, diantaranya adalah sumber daya manusia, modal kerja, dan keterlambatan proyek. Faktor lain yang berpengaruh terhadap keterlambatan proyek adalah kurangnya modal kerja atau pendanaan. Modal kerja yang ada saat ini belum bisa membiayai seluruh proyek yang menjadi tanggung jawab divisi Manajemen Proyek dan Jasa (MPJ) sebagai salah satu core bisnis perusahaan. Selain itu, realisasi kinerja divisi Manajemen Proyek dan Jasa sebagai "order generator" masih sering kali meleset dari target yang telah ditentukan. Setelah dianalisis, kondisi tersebut terjadi karena terdapat ketidakselarasan pengukuran kinerja dari korporat dengan divisi di bawahnya, sehingga menjadikan kurangnya pengawasan dan kurangnya kesesuaian penilaian kinerja antara divisi dengan perusahaan.

Setiap perusahaan seharusnya perlu untuk melakukan kegiatan evaluasi terhadap kinerja manajemen strategisnya. Perusahaan dalam hal ini perlu melakukan evaluasi disebabkan oleh persaingan bisnis yang semakin ketat. Kondisi persaingan yang ketat ini dapat membuat perusahaan menjadi sulit untuk mendapatkan order dan sulit mengambil alih pasar. Evaluasi strategi penting dilakukan perusahaan untuk dapat bersaing dengan lingkungan kompetisi bisnis yang ketat dan dinamis dimana faktor-faktor yang memengaruhi berjalannya bisnis akan berubah dengan cepat. Sehingga, dalam upaya untuk mengevaluasi dan mendukung tercapainya tujuan perusahaan, salah satu kegiatan yang penting bagi perusahaan adalah dengan melakukan perbaikan pengukuran kinerja.

PT Boma Bisma Indra diketahui telah memiliki sistem pengukuran kinerja berbasis Balanced Scorecard (BSC), dimana terdapat empat perspektif yang menjadi tolok ukur keberhasilan kinerja perusahaan yang terdiri dari aspek keuangan, aspek pelanggan, aspek bisnis internal, dan aspek pertumbuhan dan pembelajaran. Namun, strategi yang telah terbentuk dengan baik tersebut belum sampai pada tingkat divisi. Hal ini menyebabkan strategi perusahaan belum berjalan dengan baik sehingga menimbulkan masalah seperti yang terjadi pada divisi Manajemen Proyek dan Jasa. Agar target perusahaan dapat tercapai dengan maksimal, maka perlu adanya penurunan dan penyelarasan strategi perusahaan ke divisi di bawahnya.

\section{II.LANDASAN TEORI}

\section{A. Heavy Industry}

Industri adalah kegiatan ekonomi yang mengolah bahan mentah, bahan baku, barang setengah jadi dan atau barang jadi menjadi barang dengan nilai yang lebih tinggi dari penggunaannya, termasuk kegiatan rancang bangun industri dan perekayasaan industri. Terdapat berbagai klasifikasi industri yang dikelompokkan sesuai dengan kriteria masingmasing [1]. Industri berat (heavy industry) adalah industriindusti yang dalam kegiatannya mempergunakan mesin- 
mesin berat, mengolah bahan mentah dalam jumlah yang sangat banyak, dan memproduksinya pun berupa barangbarang dalam kategori tahan lama dan berat [2].

\section{B. Proyek}

Proyek merupakan suatu kegiatan sementara yang berlangsung dalam jangka waktu terbatas, dengan alokasi sumber dana tertentu dan dimaksudkan untuk melaksanakan tugas yang sasarannya telah digariskan dengan tegas. Proyek adalah suatu usaha yang bersifat sementara untuk menghasilkan suatu produk atau layanan yang unik [3].

\section{Balanced Scorecard}

Balanced scorecard (BSC) merupakan sistem pengukuran kinerja yang berfokus pada aspek keuangan dan non keuangan dengan memandang 4 perspektif BSC, yaitu keuangan, pelanggan, proses bisnis internal, serta pembelajaran dan pertumbuhan karyawan. Balanced scorecard membantu organisasi untuk menghadapi dua masalah fundamental, yaitu mengukur kinerja organisasi secara efektif dan menerapkan strategi dengan sukses [4].

\section{D.Strategy Map}

Strategy map adalah sebuah diagram yang menggambarkan hubungan antara empat perspektif dalam BSC, yaitu financial perspective, customer perspective, internal business process perspective, dan learning and growth perspective. Keempat perspektif ini memiliki tujuantujuan yang masing-masing memiliki hubungan kausal. Strategy map menyediakan sebuah framework untuk menjelaskan bagaimana sebuah strategi menghubungkan intangible asset dalam proses menciptakan nilai untuk tujuan jangka panjang [5].

\section{E. Key Performance Indicator (KPI)}

Key Performance Indicator (KPI) adalah suatu variabel yang digunakan untuk mengekspresikan secara kuantitatif efektivitas dan efisiensi proses atau operasi dengan berpedoman pada target dan tujuan organisasi sebagai alat untuk menilai keberhasilan pencapaian tujuan organisasi yang diwujudkan dalam ukuran-ukuran tertentu [6].

\section{F. Cascading}

Cascading adalah proses penyusunan scorecard di setiap jenjang organisasi oleh manajer organisasi dengan menggunakan scorecard jenjang organisasi di atasnya sebagai basis. Atau cascading merupakan alat untuk mengomunikasikan sasaran dan inisiatif strategik jenjang organisasi tertinggi ke setiap jenjang organisasi yang berada di bawahnya [7].

\section{G.Analytical Hierarchy Process}

Analytical Hierarchy Process (AHP) merupakan suatu pendekatan praktis untuk memecahkan masalah keputusan kompleks yang meliputi perbandingan alternatif [8]. AHP merupakan prosedur terstruktur dan sistematis yang digunakan untuk menguraikan masalah multi faktor atau multi kriteria yang kompleks menjadi suatu hierarki dari tingkat tertinggi hingga tingkat terendah. Hierarki didefinisikan sebagai suatu representasi dari sebuah permasalahan yang kompleks dalam suatu struktur multi- level dimana level pertama adalah tujuan, diikuti oleh faktor kriteria, sub kriteria dan seterusnya ke bawah hingga level terakhir dari alternatif [9].

\section{METODOLOGI PENELITIAN}

\section{A. Tahap Identifikasi Potensi Penelitian}

Pada tahapan ini dilakukan identifikasi permasalahan pada divisi MPJ dan juga permasalahan pengukuran kinerja dengan melakukan wawancara semi-terstruktur dan studi literatur.

B. Cascading dari BSC Perusahaan dan Identifikasi Sasaran Strategis

Melakukan penurunan sasaran strategis dari BSC perusahaan ke divisi MPJ dan melakukan identifikasi sasaran strategis melalui output dan stakeholder expectation berdasarkan RKAP, RJPP, dan job description.

\section{Verivikasi Sasaran Strategis Divisi MPJ}

Menyebarkan kuesioner verifikasi sasaran strategis divisi MPJ kepada stakeholder divisi untuk memperoleh sasaran strategis yang benar-benar sesuai dengan proses bisnis divisi MPJ.

\section{Merumuskan Strategy Map dan Membuat KPI Divisi MPJ}

Menerjemahkan sasaran strategis ke Strategy Map Divisi MPJ dan membuat KPI pada masing-masing sasaran strategis agar memiliki alat ukur.

\section{E. Pembobotan Perspektif, Sasaran Strategis, dan KPI Divisi $M P J$}

Melakukan pembobotan perspektif, sasaran strategis, dan KPI divisi MPJ menggunakan metode Analytical Hierarchy Process yang dibantu oleh software Expert Choice

F. Cascading dari BSC Divisi MPJ ke Departemen Engineering dan Departemen Konstruksi

Melakukan penurunan dari sasaran strategis divisi MPJ ke departemen Engineering dan departemen Konstruksi dan identifikasi sasaran strategis pada masing-masing departemen output dan stakeholder expectation berdasarkan job description.

\section{G.Merumuskan Strategy Map dan Membuat KPI Departemen}

Menerjemahkan sasaran strategis ke Strategy Map departemen Engineering dan departemen Konstruksi dan membuat KPI pada masing-masing sasaran strategis tiap departemen agar memiliki alat ukur.

\section{H.Pembobotan Perspektif, Sasaran Strategis, dan KPI}

Departemen Engineering dan Departemen Konstruksi

Melakukan pembobotan perspektif, sasaran strategis, dan KPI departemen Engineering dan departemen Konstruksi menggunakan metode Analytical Hierarchy Process yang dibantu oleh software Expert Choice.

\section{Melakukan Scoring terhadap KPI Divisi MPJ}

Studi literatur mengenai konsep perhitungan scoring, menetapkan target pada masing-masing indikator warna pada traffic light system, dan melakukan scoring dengan wawancara pada masing-masing bidang yang bertanggung jawab pada masing-masing KPI. 


\section{HASIL DAN DISKUSI}

\section{A. Profil Perusahaan}

1) Visi Perusahaan

Menjadi perusahaan sehat, berdaya saing, dan inovatif yang bergerak di bidang manufaktur peralatan industri, manajemen proyek dan services baik di kawasan domestik maupun regional.

2) Misi Perusahaan

Menumbuhkan industri antara (EPC, EPM \& Services) yang bertumpu pada kearifan lokal untuk mendukung industri hulu dan hilir baik pasar domestik maupun ekspor.

3) Bidang Usaha

Tabel 1.

Produk divisi Mesin Peralatan Industri (MPI)

\begin{tabular}{cccl}
\hline \hline Lokasi & Bidang Usaha & & Produk \\
\hline Pasuruan & Manufacturing & 1. & Condensers \\
& & 2. & Pressure Vessels \\
& & 3. & Heat \\
& & 4. & Automotors \\
& & 5. & Parts \\
& & & \\
\hline \hline
\end{tabular}

Tabel 2.

Produk divisi Manajemen Proyek dan Jasa (MPJ)

\begin{tabular}{cll}
\hline \hline Lokasi & Bidang Usaha & \multicolumn{1}{c}{ Produk } \\
\hline Surabaya & Project & Sub-System for Refinery \\
& Management & Sub-System for Gas Processing Plants \\
& and Machining & Sub-System for Oil and Gas Storage \\
& Terminal Mills and Sugar Mill \\
& CPO Mevitalization \\
& Geothermal and Power Plants \\
& Workshop Machining Centre \\
& EPC Conveyor \\
& Tank Fabrication \\
& Sub-System for Cement Plants \\
& Sub-Systems for Fertilizer Plants \\
\hline \hline
\end{tabular}

B. Cascading Divisi Manajemen Proyek dan Jasa

1) Identifikasi strategi perusahaan yang relevan

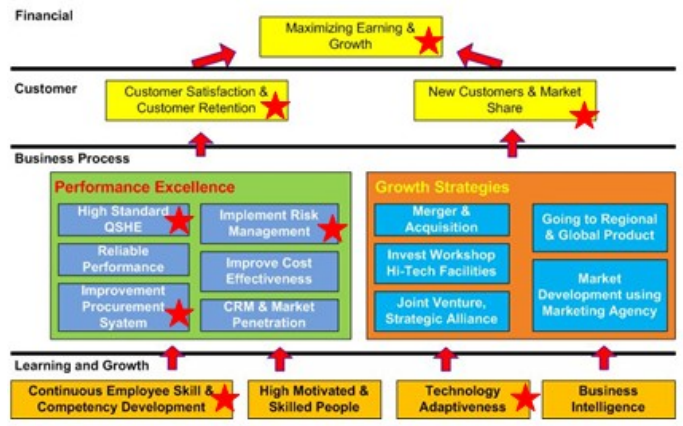

Gambar 1. Strategi perusahaan yang relevan.

Strategi yang bertanda bintang merupakan strategi yang pencapaiannya dikontribusikan oleh divisi MPJ. Strategistrategi tersebut berikutnya akan diselaraskan dengan strategi divisi MPJ berdasarkan output dan stakeholder expectation.

2) Identifikasi output dan stakeholder expectation

Tabel 3.

Output dan stakeholder expectation

\begin{tabular}{cccl}
\hline \hline No & Output & Customer & \multicolumn{1}{c}{ Expectation } \\
\hline 1 & $\begin{array}{l}\text { Keuntungan } \\
\text { divisi }\end{array}$ & Perusahaan & $\begin{array}{l}\text { Keuntungan divisi yang semakin } \\
\text { meningkat setiap tahunnya }\end{array}$ \\
2 & $\begin{array}{l}\text { Keuntungan } \\
\text { divisi }\end{array}$ & Perusahaan & $\begin{array}{l}\text { Harga Pokok Proyek yang } \\
\text { optimal agar memperoleh margin } \\
\text { setinggi-tingginya }\end{array}$
\end{tabular}

\begin{tabular}{|c|c|c|c|}
\hline No & Output & Customer & Expectation \\
\hline 3 & $\begin{array}{l}\text { Proses bisnis } \\
\text { divisi MPJ } \\
\text { yang berhasil } \\
\text { dilakukan } \\
\text { mitigasi } \\
\text { risiko }\end{array}$ & Divisi MPJ & $\begin{array}{l}\text { Terlaksananya mitigasi risiko } \\
\text { pada setiap proses bisnis divisi } \\
\text { MPJ yang perlu dilakukan } \\
\text { mitigasi }\end{array}$ \\
\hline 4 & $\begin{array}{l}\text { Fasilitas } \\
\text { lapangan } \\
\text { yang lengkap }\end{array}$ & Proyek & $\begin{array}{l}\text { Fasilitas lapangan yang lengkap } \\
\text { untuk mendukung pelaksanaan } \\
\text { proyek di site }\end{array}$ \\
\hline 5 & $\begin{array}{l}\text { Order yang } \\
\text { bertambah }\end{array}$ & Perusahaan & $\begin{array}{l}\text { Meningkatnya order/contract } \\
\text { booked }\end{array}$ \\
\hline 6 & $\begin{array}{l}\text { Kepuasan } \\
\text { pelanggan }\end{array}$ & Pelanggan & $\begin{array}{l}\text { Proyek yang dilaksanakan } \\
\text { secara tepat waktu, tepat } \\
\text { anggaran dan tepat kualitas }\end{array}$ \\
\hline 7 & $\begin{array}{l}\text { Fasilitas } \\
\text { produksi }\end{array}$ & Divisi MPJ & Meningkatnya fasilitas produksi \\
\hline 8 & $\begin{array}{l}\text { Jumlah } \\
\text { produksi } \\
\text { bertambah }\end{array}$ & Divisi MPJ & $\begin{array}{l}\text { Fasilitas produksi yang } \\
\text { digunakan secara optimal }\end{array}$ \\
\hline 9 & $\begin{array}{l}\text { Menambah } \\
\text { jumlah } \\
\text { partner } \\
\text { strategis }\end{array}$ & Divisi MPJ & $\begin{array}{l}\text { Jumlah partner strategis yang } \\
\text { semakin bertambah }\end{array}$ \\
\hline 10 & $\begin{array}{l}\text { Produktivitas } \\
\text { yang } \\
\text { maksimal }\end{array}$ & Divisi MPJ & $\begin{array}{l}\text { Sumber Daya Manusia yang } \\
\text { optimal }\end{array}$ \\
\hline
\end{tabular}

3) Sasaran strategis divisi MPJ

Tabel 4.

Sasaran strategis divisi MPJ

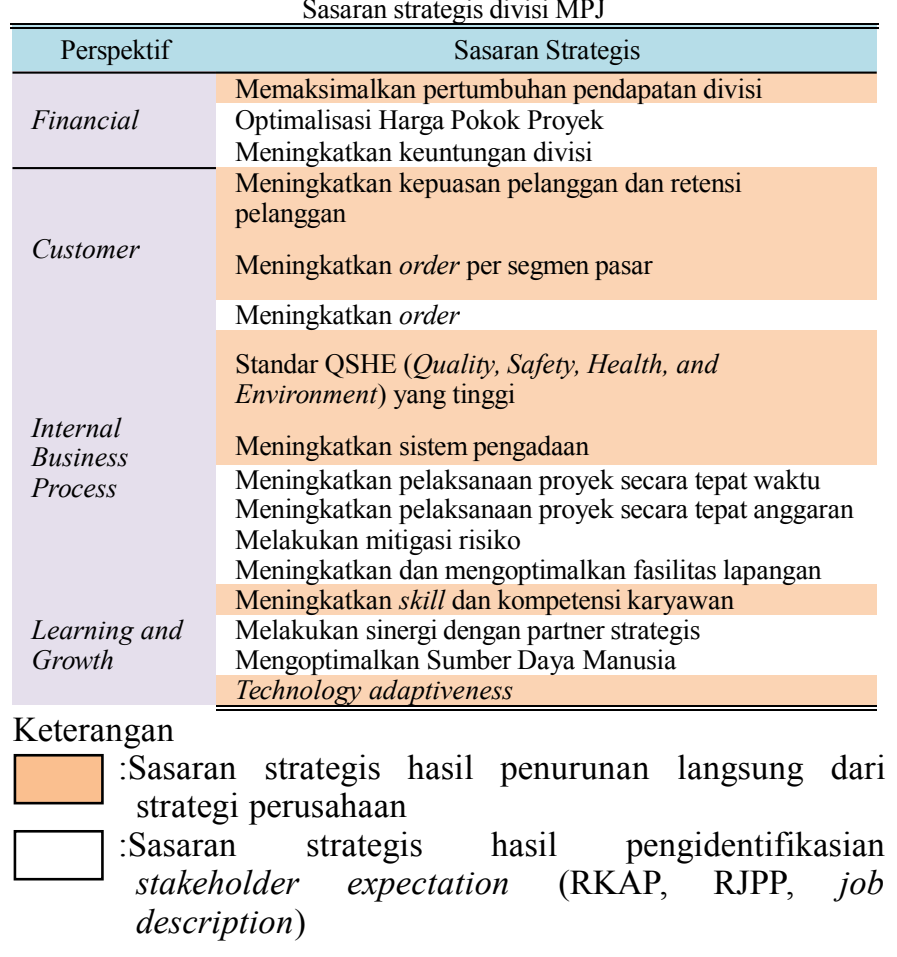


4) Strategy map divisi MPJ

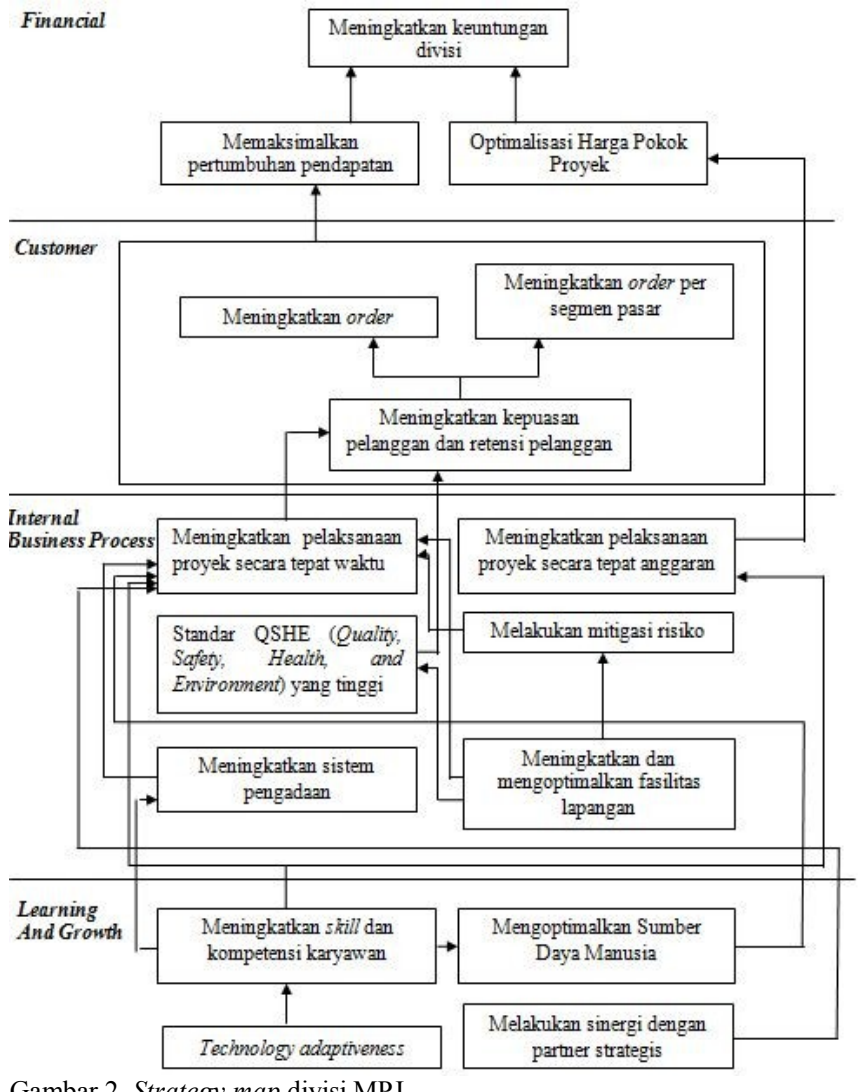

Gambar 2. Strategy map divisi MPJ. keinginan pelanggan

\section{5) KPI divisi MPJ}

Tabel 5.

KPI divisi MPJ

\begin{tabular}{|c|c|c|c|}
\hline Perspektif & Sasaran Strategis & KPI & Sifat \\
\hline \multirow{3}{*}{ Financial } & $\begin{array}{l}\text { Memaksimalkan } \\
\text { pertumbuhan pendapatan } \\
\text { divisi }\end{array}$ & $\begin{array}{l}\text { Persentase tingkat } \\
\text { pertumbuhan } \\
\text { pendapatan divisi }\end{array}$ & HB \\
\hline & $\begin{array}{l}\text { Optimalisasi Harga Pokok } \\
\text { Proyek }\end{array}$ & $\begin{array}{l}\text { Persentase HPP } \\
\text { dengan penjualan }\end{array}$ & $\mathrm{HB}$ \\
\hline & $\begin{array}{l}\text { Meningkatkan keuntungan } \\
\text { divisi }\end{array}$ & Net margin divisi & HB \\
\hline \multirow{8}{*}{ Customer } & $\begin{array}{l}\text { Meningkatkan kepuasan } \\
\text { pelanggan dan retensi } \\
\text { pelanggan }\end{array}$ & $\begin{array}{l}\text { Persentase } \\
\text { pelanggan yang } \\
\text { puas }\end{array}$ & $\mathrm{HB}$ \\
\hline & & $\begin{array}{l}\text { Persentase jumlah } \\
\text { perusahaan yang } \\
\text { melakukan } \\
\text { reorder }\end{array}$ & $\mathrm{HB}$ \\
\hline & & $\begin{array}{l}\text { Persentase } \\
\text { peningkatan } \\
\text { pelanggan agro }\end{array}$ & $\mathrm{HB}$ \\
\hline & & Persentase & \\
\hline & $\begin{array}{l}\text { Meningkatkan order per } \\
\text { segmen pasar }\end{array}$ & $\begin{array}{l}\text { peningkatan } \\
\text { pelanggan } \text { power } \\
\text { plant }\end{array}$ & $\mathrm{HB}$ \\
\hline & & $\begin{array}{l}\text { Persentase } \\
\text { peningkatan } \\
\text { pelanggan oil \& }\end{array}$ & $\mathrm{HB}$ \\
\hline & & $\begin{array}{l}\text { gas industrial } \\
\text { Persentase }\end{array}$ & \\
\hline & Meningkatkan order & $\begin{array}{l}\text { peningkatan } \text { order } \\
\text { yang masuk }\end{array}$ & HB \\
\hline $\begin{array}{l}\text { Internal } \\
\text { business } \\
\text { process }\end{array}$ & $\begin{array}{l}\text { Standar QSHE (Quality, } \\
\text { Safety, Health, and } \\
\text { Environment) yang tinggi }\end{array}$ & $\begin{array}{l}\text { Persentase jumlah } \\
\text { kualitas } \\
\text { pengerjaan proyek } \\
\text { yang tidak sesuai } \\
\text { dengan standar dan }\end{array}$ & LB \\
\hline
\end{tabular}




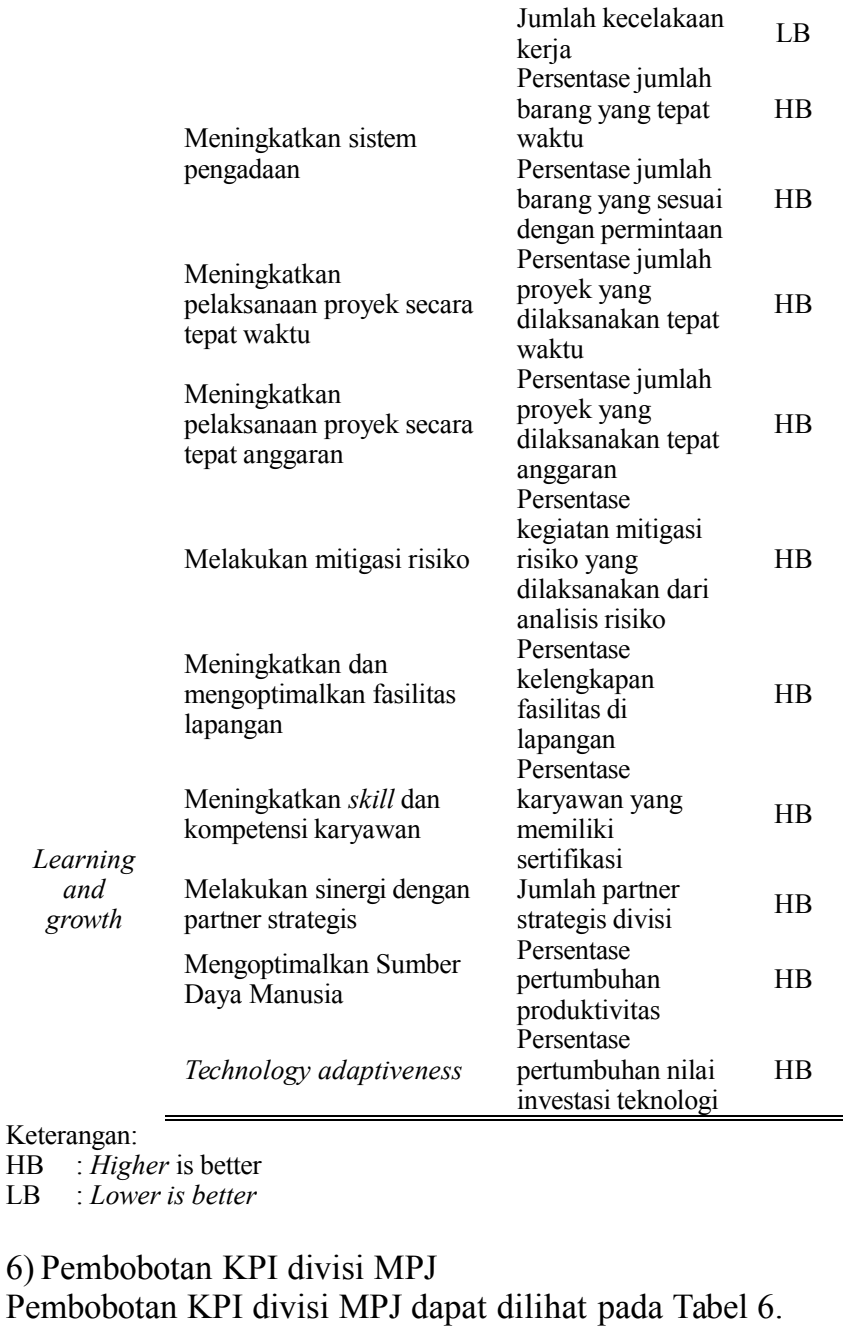

\section{Scoring KPI divisi MPJ}

Bagian ini menunjukkan hasil uji coba penilaian kinerja divisi MPJ yang dilakukan berdasarkan traffic light system. Penentuan batas pencapaian tiap warna dilakukan dengan wawancara kepada expert. Berikut ini merupakan rincian target pencapaian tiap warna pada traffic light system. (Tabel 7)

1) Warna hijau: skor KPI $71-100 \%$

Warna ini menunjukkan bahwa pencapaian KPI sudah sangat baik sehingga pencapaian KPI tersebut perlu dipertahankan oleh pihak manajemen.

$$
\text { Tabel } 6 .
$$

Bobot perspektif dan KPI

\begin{tabular}{cccc}
\hline \hline Perspektif & $\begin{array}{c}\text { Bobot } \\
\text { Perspektif }\end{array}$ & \multicolumn{1}{c}{ KPI } & $\begin{array}{c}\text { Bobot KPI } \\
\text { Global }\end{array}$ \\
\hline Financial & 0.383 & $\begin{array}{l}\text { Persentase tingkat } \\
\text { pertumbuhan pendapatan } \\
\text { divisi } \\
\text { Persentase HPP dengan } \\
\text { penjualan }\end{array}$ & 0.108006 \\
\hline Customer & 0.293 & $\begin{array}{l}\text { Net margin divisi } \\
\text { Persentase pelanggan yang } \\
\text { puas }\end{array}$ & 0.102261 \\
& & $\begin{array}{l}\text { Persentase jumlah perusahaan } \\
\text { yang melakukan reorder }\end{array}$ & 0.172733 \\
& & $\begin{array}{l}\text { Persentase peningkatan } \\
\text { pelanggan agro }\end{array}$ & 0.040868 \\
& & $\begin{array}{l}\text { Persentase peningkatan } \\
\text { pelanggan power plant }\end{array}$ & 0.012329 \\
& & $\begin{array}{l}\text { Persentase peningkatan } \\
\text { pelanggan oil \& gas }\end{array}$ & 0.026508 \\
& & 0.038220
\end{tabular}

industrial

Tabel 7.

Hasil scoring KPI divisi MPJ

\begin{tabular}{|c|c|c|c|c|}
\hline Perspektif & KPI & Target & Aktual & Skor \\
\hline \multirow{3}{*}{ Financial } & $\begin{array}{l}\text { Persentase tingkat } \\
\text { pertumbuhan } \\
\text { pendapatan divisi }\end{array}$ & $33 \%$ & $27.62 \%$ & 0.836 \\
\hline & $\begin{array}{l}\text { Persentase HPP dengan } \\
\text { penjualan }\end{array}$ & $87 \%$ & $94 \%$ & 0.919 \\
\hline & Net margin divisi & $8 \%$ & $6 \%$ & 0.75 \\
\hline \multirow{10}{*}{ Customer } & $\begin{array}{l}\text { Persentase pelanggan } \\
\text { yang puas }\end{array}$ & $90 \%$ & - & 0 \\
\hline & $\begin{array}{l}\text { Persentase jumlah } \\
\text { perusahaan yang } \\
\text { melakukan reorder }\end{array}$ & $85 \%$ & $70.80 \%$ & 0.832 \\
\hline & $\begin{array}{l}\text { Persentase peningkatan } \\
\text { pelanggan agro }\end{array}$ & $7 \%$ & $-8 \%$ & 0.00 \\
\hline & $\begin{array}{l}\text { Persentase peningkatan } \\
\text { pelanggan } \text { power plant }\end{array}$ & $22 \%$ & $16 \%$ & 0.727 \\
\hline & $\begin{array}{l}\text { Persentase peningkatan } \\
\text { pelanggan oil \& gas } \\
\text { industrial }\end{array}$ & $60 \%$ & $44 \%$ & 0.733 \\
\hline & $\begin{array}{l}\text { Persentase peningkatan } \\
\text { order yang masuk }\end{array}$ & $50 \%$ & $42 \%$ & 0.84 \\
\hline & $\begin{array}{l}\text { Persentase jumlah } \\
\text { kualitas pengerjaan } \\
\text { proyek yang tidak sesuai } \\
\text { dengan standar dan } \\
\text { keinginan pelanggan }\end{array}$ & $3 \%$ & $0.005 \%$ & 1 \\
\hline & $\begin{array}{l}\text { Jumlah kecelakaan } \\
\text { kerja }\end{array}$ & 0 & 0 & 1 \\
\hline & $\begin{array}{l}\text { Persentase jumlah } \\
\text { barang yang tepat waktu }\end{array}$ & $80 \%$ & - & 0 \\
\hline & $\begin{array}{l}\text { Persentase jumlah } \\
\text { barang yang sesuai } \\
\text { dengan permintaan }\end{array}$ & $95 \%$ & $92 \%$ & 0.968 \\
\hline \multirow[t]{5}{*}{$\begin{array}{l}\text { Internal } \\
\text { business } \\
\text { process }\end{array}$} & $\begin{array}{l}\text { Persentase jumlah } \\
\text { proyek yang } \\
\text { dilaksanakan tepat } \\
\text { waktu }\end{array}$ & $90 \%$ & $65 \%$ & 0.722 \\
\hline & $\begin{array}{l}\text { Persentase jumlah } \\
\text { proyek yang } \\
\text { dilaksanakan tepat } \\
\text { anggaran }\end{array}$ & $90 \%$ & $80 \%$ & 0.888 \\
\hline & $\begin{array}{l}\text { Persentase kegiatan } \\
\text { mitigasi risiko yang } \\
\text { dilaksanakan dari } \\
\text { analisis risiko }\end{array}$ & $100 \%$ & $100 \%$ & 1 \\
\hline & $\begin{array}{l}\text { Persentase kelengkapan } \\
\text { fasilitas di lapangan }\end{array}$ & $100 \%$ & $97 \%$ & 0.97 \\
\hline & $\begin{array}{l}\text { Persentase karyawan } \\
\text { yang memiliki } \\
\text { sertifikasi }\end{array}$ & $30 \%$ & $20 \%$ & 0.666 \\
\hline \multirow{3}{*}{$\begin{array}{l}\text { Learning } \\
\text { and growth }\end{array}$} & $\begin{array}{l}\text { Jumlah partner strategis } \\
\text { divisi }\end{array}$ & $\begin{array}{c}45 \\
\text { partner }\end{array}$ & $\begin{array}{c}33 \\
\text { partner }\end{array}$ & 0.733 \\
\hline & $\begin{array}{l}\text { Persentase pertumbuhan } \\
\text { produktivitas }\end{array}$ & $30 \%$ & - & 0 \\
\hline & $\begin{array}{l}\text { Persentase pertumbuhan } \\
\text { nilai investasi teknologi }\end{array}$ & $20 \%$ & 0 & 0 \\
\hline
\end{tabular}




\begin{tabular}{|c|c|c|c|}
\hline & & $\begin{array}{l}\text { Persentase peningkatan order } \\
\text { yang masuk }\end{array}$ & 0.143863 \\
\hline \multirow{8}{*}{$\begin{array}{l}\text { Internal } \\
\text { business } \\
\text { process }\end{array}$} & \multirow{8}{*}{0.189} & $\begin{array}{l}\text { Persentase jumlah kualitas } \\
\text { pengerjaan proyek yang tidak } \\
\text { sesuai dengan standar dan } \\
\text { keinginan pelanggan }\end{array}$ & 0.011067 \\
\hline & & Jumlah kecelakaan kerja & 0.011990 \\
\hline & & $\begin{array}{l}\text { Persentase jumlah barang } \\
\text { yang tepat waktu }\end{array}$ & 0.011830 \\
\hline & & $\begin{array}{l}\text { Persentase jumlah barang } \\
\text { yang sesuai dengan } \\
\text { permintaan }\end{array}$ & 0.010282 \\
\hline & & $\begin{array}{l}\text { Persentase jumlah proyek } \\
\text { yang dilaksanakan tepat } \\
\text { waktu }\end{array}$ & 0.046305 \\
\hline & & $\begin{array}{l}\text { Persentase jumlah proyek } \\
\text { yang dilaksanakan tepat } \\
\text { anggaran }\end{array}$ & 0.056889 \\
\hline & & $\begin{array}{l}\text { Persentase kegiatan mitigasi } \\
\text { risiko yang dilaksanakan dari } \\
\text { analisis risiko }\end{array}$ & 0.023058 \\
\hline & & $\begin{array}{l}\text { Persentase kelengkapan } \\
\text { fasilitas di lapangan }\end{array}$ & 0.017577 \\
\hline \multirow{4}{*}{$\begin{array}{l}\text { Learning } \\
\text { and } \\
\text { growth }\end{array}$} & \multirow{4}{*}{0.135} & $\begin{array}{l}\text { Persentase karyawan yang } \\
\text { memiliki sertifikasi }\end{array}$ & 0.061695 \\
\hline & & Jumlah partner strategis divisi & 0.018765 \\
\hline & & $\begin{array}{l}\text { Persentase pertumbuhan } \\
\text { produktivitas }\end{array}$ & 0.032535 \\
\hline & & $\begin{array}{l}\text { Persentase pertumbuhan nilai } \\
\text { investasi teknologi }\end{array}$ & 0.022005 \\
\hline
\end{tabular}

2) Warna kuning: skor KPI $51-70 \%$

Warna ini menunjukkan bahwa pencapaian KPI masih belum memuaskan, sehingga pihak manajemen perlu berwaspada dan mencari tindakan yang perlu dilakukan untuk meningkatkan pencapaian KPI tersebut.

3) Warna merah: skor KPI 0-50\%

Warna ini menunjukkan bahwa pencapaian KPI masih jauh di bawah target, sehingga pihak manajemen perlu melakukan tindakan yang lebih serius agar dapat meningkatkan pencapaian KPI tersebut.

\section{D.Implikasi manajerial}

Dari hasil uji coba pengukuran kinerja tahun 2018, terdapat beberapa KPI divisi MPJ yang masih berwarna merah. Dalam hal ini pihak manajemen harus melakukan tindakan-tindakan yang diutamakan pada KPI tersebut, terutama pada perspektif yang memiliki bobot lebih tinggi. Selain itu, terdapat satu buah KPI berwarna kuning yang juga perlu diperhatikan oleh pihak manajemen. Selebihnya, KPI yang berwarna hijau perlu dipertahankan pencapaiannya, namun peningkatan juga tentunya harus terus dilakukan.

\section{V.KESIMPULAN DAN SARAN}

\section{A. Kesimpulan}

Kesimpulan dari penelitian ini adalah:

1) Dihasilkan strategy map divisi MPJ, departemen Engineering, dan departemen Konstruksi

2) Dihasilkan 16 sasaran strategis dan 21 KPI divisi MPJ, 8 sasaran strategis dan $10 \mathrm{KPI}$ departemen Engineering, dan 9 sasaran strategis dan 10 KPI departemen Konstruksi.

3) Dari hasil scoring KPI yang dilakukan pada divisi MPJ tahun 2018 diperoleh 15 KPI berwarna hijau, 1 KPI berwarna kuning, dan 5 KPI berwarna merah. Dari hasil tersebut dapat disimpulkan bahwa secara keseluruhan kinerja divisi MPJ pada tahun 2018 adalah baik.

\section{B. Saran}

Saran yang dapat diberikan pada penelitian ini adalah:

1) Untuk perusahaan, perlu adanya pemahaman kepada seluruh karyawan terkait KPI, diperlukan sistem pencatatan seluruh kegiatan dan pembuatan laporan perusahaan yang baik dan lengkap, perlu juga adanya pengembangan pembuatan dashboard yang terintegrasi.

2) Untuk penelitian selanjutnya, penelitian cascading BSC ini masih pada tingkatan divisi MPJ, departemen Engineering, dan departemen Konstruksi. Sehingga, perlu adanya penelitian lebih lanjut untuk menghasilkan BSC pada tingkatan di bawahnya hingga tingkat individu.

\section{DAFTAR PUSTAKA}

[1] Kartasapoetra, Teknologi Konservasi Tanah dan Air. Jakarta: PT Rineka Cipta, 2000.

[2] I. Abdurachmat and E. Maryani, "Geografi Ekonomi," Bandung, 1997.

[3] I. Soeharto, Manajemen Proyek dari Konseptual Sampai Operasional. Jakarta: Penerbit Erlangga, 2012.

[4] Sukardi, Balanced Scorecard. Jakarta: Bumi Aksara, 2003

[5] R. S. Kaplan and D. Norton, Strategy Maps. Massachusets: Harvard Business School Press Boston, 2004.

[6] Lohman, Analisis Kuantitatif. Yogyakarta: Erlangga, 2003.

[7] Risna and Mustafa, "Penyelesaian Perjanjian Pembiayaan Konsumen dengan Jaminan Fidusia dalam Hal Konsumen Wanprestasi di PT Mandala Multifinance Tbk. Cabang Makassar," 2008.

[8] A. Badiru and P. Pulat, Comprehensif Project Management: Integrating Optimation Models. New Jersey: Prentice Hall, 1995.

[9] L. Saaty, The Analytical Hierarchy Process. New York: New York, 1980 . 